\title{
Adoption factors of electronic health record systems
}

\author{
Daria Spatar ${ }^{\mathrm{a}}$, Orhun Kok ${ }^{\mathrm{b}}$, Nuri Basoglu ${ }^{\mathrm{c}}$, Tugrul Daim ${ }^{\mathrm{a}, *}$

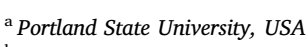 \\ ' Timac Agro Avrasya, Turkey \\ ${ }^{\mathrm{c}}$ Izmir Institute of Technology, Turkey
}

\section{A B S T R A C T}

The main goal of the study is to investigate the factors that affect adoption of EHR systems. The adoption has been looked at through four lenses: users' satisfaction, impact on quality of care, infusion and diffusion of the technology. The study incorporates the results of the most important studies in the field. The findings of the research allow decision-makers to select an EHR that better suits needs of the users, to choose a strategy to avoid users' resistance and lack of support. The study offers a comprehensive framework that can be used in different settings, i.e. small and large clinics, developing and developed countries, etc. Also it contributes to the state of knowledge, as it provides an extensive analysis of the factors, both system- and user-related, that affect user adoption and proves applicability of TAM in the healthcare settings.

\section{Introduction}

The need for storing patient's medical information electronically instead of on paper was realized in the 1960s. Around that time a couple of clinics developed their own Electronic Health Records (EHR) systems [1]. Over time with the development of computers, evolution and widespread of the Internet, and changes in health care more and more hospitals and health system organizations were moving toward adoption and implementation of such systems [2]. In 2012 EHR usage rate among office-based physicians has reached the $72 \%$ level [3].

While implementing EHR systems, organizations seek to accomplish such objectives as improved patient safety and physicians efficiency [4], getting information for better decision making [5], and increased accuracy and reliability of medical data. Despite the benefits of the EHRs and government stimulation to their adoption, healthcare organizations are facing great difficulties trying to implement and adopt the systems and about 30\% of EHR implementations fail [5]. One the main reasons of failures is lack of adoption by users [5].

In order to achieve successful adoption of the technology it is important to understand the factors that determine it. One of the most widely used frameworks for IT adoption is Technology Acceptance Model (TAM) developed by Fred Davis [6]. This model has been applied for different technologies and in different sectors [7]. The authors of the current paper have had prior experience with applying TAM and have shown its usability to study adoption of ERP systems [7], mobile services [8,9], diet software [10], online flight reservation service [11]. They have also proved its applicability in the health care settings, e.g. for determining patient preferences for remote monitoring [12], factors for health information service adoption [13]. The present study is applying TAM to explore success factors of EHR adoption. The earlier results of the study, were reported in [14-17].

\section{Literature review}

The literature review has shown that Technology Acceptance Model (TAM) [6] proposed by Fred Davis is applicable in the healthcare settings and provides solid basis for explaining users' intention to use HIT solutions [18-21]. TAM suggests that attitude, perceived usefulness, and perceived ease of use affect an intention to accept technology [6]. Perceived ease of use is defined as the degree of effort, which a person believes to put in order to use a particular system. Davis indicates that effort is a finite resource that a person may allocate to the various activities for which he or she is responsible, so people would prefer a system free of effort [6]. Perceived usefulness is defined as degree of performance improvement that a person believes to achieve by using a particular system [6]. According to Davis, a system high in perceived usefulness, in turn, is one for which a user believes in the existence of a positive use-performance relationship [6]. In TAM, also, all other external variables are mediated by perceived usefulness and perceived ease of use $[6,10]$. Several studies that replicated the work of Fred Davis also specified that ease of learning was impacting perceived ease of use [22,23]. The significance of the relationship between TAM constructs in the healthcare settings was proved in multiple studies. The paper by Richard J. Holden and Ben-Tzion Karsh provided a detailed overview of TAM applicability in healthcare [24]. Research conducted in the healthcare settings also supported that ease of learning had a

\footnotetext{
* Corresponding author.

E-mail address: ji2td@pdx.edu (T. Daim).
} 
significant and positive effect on perceived ease of use [25].

The literature review revealed a number of indicators of successful EHR adoption: users satisfaction, technology infusion and diffusion, and quality of care. User satisfaction was identified as one of the main dimensions of information systems success by many authors in the field [7,26]. According to the study by Sánchez and colleagues [27] this indicator was also an important dimensions for evaluation of successfulness of implementation of EHR system. The study by Lee and colleague showed that such EHR characteristics as productivity and ease of use were highly correlated with users satisfaction [28]. The relation between ease of use and satisfaction was also supported by O'Connell and colleagues, they noted that systems that users found hard to use often left them dissatisfied [29]. Lack of perceived usefulness was also found to be a potential barrier toward users' satisfaction [30].

Technology infusion is defined as "the extent to which the full potential of the innovation has been embedded within an individual's or organizational work system" $[31,32]$. In other words it means how an individual uses the offerings and benefits of the system, how deeply the system is integrated with existing processes, how many tasks are addressed with the technology. The studies showed that EHR system that is designed without attention to end users' needs and thus perceived by them as difficult to use and inconvenient would lead to inefficiency, workarounds and low integration with existing processes [33]. Full potential of an EHR system would be embedded into healthcare organization only if a system simplifies users' tasks, improves their performance and enhances effectiveness [30].

The more motivated physicians are the higher diffusion rates should be expected [41]. Fichman and colleagues noted that such innovation characteristics as usefulness and ease of use had a positive effect on its diffusion [42]. Improved quality of care is another indicator that an EHR system is adopted and used properly [35,36]. Quality of care is defined as a rate of successful treatments and diagnosis made by physicians. Higher quality of care can be reached with a more useful system and a more positive approach to the EHR usage [4,37-39]. Likourezos and colleagues [40] expressed that satisfaction of nurses and physicians mainly depended on computer experience, perception regarding the usefulness of EHR and EHR's effects on quality of care. Cynthia Gadd and Louis Penrod in the study "Assessing Physician Attitudes Regarding Use of an Outpatient EMR: A Longitudinal, Multi-Practice Study" [20] concluded that physicians would more likely accept an EHR system if it facilitated efficient work, improve quality of care and made them satisfied. Improving quality and efficiency of care was also identified as one of the most important motivators to adopt an EHR system by Ross and colleagues [35].

Ross and colleagues noted that while some practices did not object to reengineering their workflows, most found it troublesome and looked for an EHR that complement their existing workflows [35]. This finding was consistent with the results of the research conducted by Sookuyng Hyun and colleagues [43] which revealed that in order to increase the adoption effectiveness, EHR systems had to be designed according to the established workflows, otherwise practical application of the EHR system would take longer than expected. A study "Adoption of electronic health records in Korean tertiary teaching and general hospitals" [44] also showed that adoption of the EHR systems had been generally blocked by the lack of understanding of clinical workflow. In order to overcome this problem Morton and Wiedenbeck [19] proposed to involve physicians in both product selection and implementation because they provide their insights on clinical workflow. Their study also revealed that there was a positive correlation between physician involvement, as well as management support and perceived ease of use. The provided the following explanations: the more time management devoted to the project of EHR implementation, the more resources it allocated the easier it would be for physician to use the system and incorporate it to their work process. Importance of flexible architecture was also underlined by Toussaint and Lobber in their paper "Component-based development for supporting workflows in hospitals" [45].
The authors stated that flexible architecture, which could easily meet new requirements and incorporate potential technological changes, was required to ensure easier adoption of health information systems requires. Alan Rose with colleagues [46] defined the relationship with the usability of EHR systems with the user interface, flexibility and workflow of the implemented system. In their paper they made recommendations about design changes to EHR user interface that would ensure usability and design consistency across other clinical applications. Also Edwards and colleagues noticed that flexibility and workflow were main elements of the usability [47].

Another characteristic of the EHR system that has a significant impact on the users' attitude toward the system is user interface. Hyun and colleagues [43] emphasized the importance of developing an interface that would be easy to use and navigate, understandable and well matched to users' tasks. The study "User acceptance of inter-organizational electronic medical records" [21] revealed such system characteristics that affect perceived ease of use as user friendly interface, ease of learning, accessibility. These findings were also supported by the research conducted by Melinda Wilkins [25] on 70 physicians. Understandable and clear interactions with EHR, ease of learning, ease of becoming skillful and ease of navigating were found to be significant factors affecting perceived ease of use. As well as flexibility of the systems user interface has a great effect on usability [47]. User interface was found to be highly correlated with task performance and completion [48]. Easy to understand and navigate interfaces supported the healthcare process and reduced medical errors, thus making the system more useful [46]. It was also found that user interface positively affects affected perceived ease of use positively [14].

Quality of the information stored in the system plays an important role, as physicians make their decisions based on the data provided by EHR and thus should have a full confidence in its accuracy [49]. Inaccurate and incomplete data could lead to inefficiency and poor adoption [50]. Topacan and colleagues [13] conducted a series of interviews with physicians to better understand their preferences regarding an electronic health service. The results indicated that appropriate, comprehensive and quality content positively affected the perceived usefulness of the service. Important characteristic of EHR system is ability to keep the correct information about medicine dosage for each patient according to his/her condition [51]. It would allow physicians to avoid polypharmacy and possibly adverse drug events and side effects, and more effectively manage the patient's treatment. There can be situations when medical records are the only source of information on a patient's medications [52]. It is crusial to keep accurate information about medications and their dosages to ensure patients' safety and improve clinical care. Updated medication lists would increase system' accuracy and usefulness [52].

The direct access to the information through filtering and search capabilities was also identified as an important factor by Xiaoyan Want and colleagues [53]. They stated that such functionality of the system as selection of the relevant information positively affected quality of care and increased the performance of diagnosis. Ease of access to the information were indicated as important issues toward successful HIT adoption by Leslie Liu and colleagues [30]. Ross and colleagues [35] underlined the importance of such functionalities of the EHR as capabilities to perform a search through patient records, report creation, and electronic prescribing. Mobility was identified as an important characteristic of EHR system, which affected perceived usefulness in a positive way [13]. The study by Virginia Ilie and colleagues [54] showed that accessibility not only affected usefulness, but also perceived ease of use. Even if a system is well designed and provide clear benefits it may not be used because it is difficult to access and reach the data. As Edwards and colleagues pointed out lack of flexibility was one of the sources of usability issues [47]. In its turn usability is directly associated with the usefulness of the EHR [55], thus the more flexible and adaptable the system is the more useful it is perceived.

Adoption success not solely depends on the technology, but also 
users' abilities, knowledge and experience play a great role. Likourezos and colleagues [40] expressed that satisfaction of nurses and physicians depended on computer experience as much as on perception regarding the use of EHR and EHR's effects on quality of care. The similar conclusion was made by Umit Topacan and colleagues [13]. Their research showed that self-efficacy had a positive effect on the ease of use. Kerimoglu and colleagues [56] stated that better adoption would be achieved if users were competent and confident, as they were not likely to instantly resist using the system at first sight. The study conducted by Morton and Wiedenbeck showed that computer experience and selfconfidence greatly affected technology acceptance [19]. Lack of training and poor computer skills often acted as adoption barriers. EHR users who were provided with a training were found to perceive the system useful [19]. Users' competence was also found to be one of the most important enablers for technology infusion [57]. Design of the systems should focus and try to resolve the issues that may becomes critical during the launching and marketing campaign of services [58].

Reviewed articles use the parameters to evaluate the adoption that can be summarized into following concepts:

- Quality of Care: rate of the productivity in healthcare services including number of successful treatments, number of successful diagnosis and etc.;

- Diffusion: how the system is spread within an organization;

- Infusion: how an individual uses the offerings and benefits of the system, how deeply the system is integrated with existing processes;

- Satisfaction: how happy an individual is to use the system. After studying finding of different studies the following factors, which affect the adoption of EHR by physicians, were identified:

- Flexibility: system's ability to adapt according to user requirements;

- User Interface: system is convenient to use, graphs, bottoms, input fields are appropriate, the overall feel of the system is satisfactory;

- Dose Functionality (FuncDose): system has a functionality to keeping dose information regarding the patient's medication;

- Mobility: ease of access to the information;

- Information Quality (Info): completeness, accuracy, relevancy of the data;

- Ease of Learning (EoL): users don't have to put much effort while starting to use the system; it also includes availability of manual, help button, hints, etc.

Based on the literature review, the results of semi-structure interviews [14] and pilot studies the multiple regressions analysis conducted the model was proposed and hypothesizes were formulated.

The hypotheses listed below were formulated and grouped under three categories.

1. Effects of main TAM constructs on dependent variables:

H1. Quality of Care, Diffusion, Infusion, and Satisfaction are positively affected by Perceived Usefulness;

H2. Quality of Care and Diffusion are positively affected by the Attitude toward using the system;

H3. Infusion and Satisfaction are significantly and positively affected by Perceived Ease of Use;

2. Relationships between main TAM constructs were analyzed as well:

H4. Perceived Usefulness of the system positively affects Attitude;

H5. Perceived Ease of Use significantly and positively affects Attitude toward suing the system;

H6. Perceived Usefulness significantly and positively affects Attitude toward suing the system.

H7. Perceived Ease of Use positively affects Perceived Usefulness;

\section{Impacts of external factors were identified:}

H8. Information quality positively and significantly impacts Perceived Usefulness;

H9. Information quality significantly affects Ease of Use.

H10. Flexibility of the system positively affects Perceived Usefulness;

H11. Mobility of the system positively affects Perceived Usefulness;

H12. Mobility of the system positively and significantly affects Perceived Ease of Use;

H13. Self-Confidence of the user positively affects Perceived Usefulness;

H14. User Interface significantly and positively affects Perceived Usefulness;

H15. User Interface positively and significantly impacts Perceived Ease of Use;

H16. System's functionality related to keeping dose information of the medication positively affects Perceived Usefulness;

H17. System's ease of learning positively impacts the system's Perceived Ease of Use.

\section{Methodology}

Data collection was performed in 2010-2011 in Turkey. First, a series of semi-structured interviews was conducted to prioritize and choose the most relevant constructs. The results of this study were presented at the PICMET conference and published in the proceedings [14].

Then two pilot studies were carried out to test the quality and reliability of the research instrument. Cronbach's alpha values felt in the range from 0.676 to 0.943 , indicating that the consistencies of the items were significant.

Web - based questionnaires were developed and sent to healthcare employees from different organizations with different purposes. Over 300 practitioners participated in the study. Most of the respondents were university graduates $(63.2 \%)$. There were two main age groups: $36-45$ years old $(43.2 \%)$ and $46-55$ years old (36.5\%). Over $80 \%$ of physicians in the survey used systems for medical purposes, rather then managerial or financial. Doctors employed in the family treatment centers constituted the majority of respondents at $85.4 \%$ percentage.

Structural equation modeling (SEM) is a collection of statistical techniques that allow study relationships between independent variables and dependent variables, which can be either factors or measured variables. SEM provides a framework for statistical analysis, which can include factors analysis, regression analysis, correlations, etc. [59].

The model is usually represented as a path diagram, where boxes and circles are connected by arrows. Observed variables are represented as rectangles or square boxes, latent factors by circles or ellipses, single headed arrows are used to define causal relationships, and double-headed arrows indicate covariances between variables.

In order to evaluate how good a model fits data chi-square test and goodness-of-fit indices are used. The most well known indices are Goodness of Fit (GFI), Tucker Lewis Index (TLI), Comparative Fit Index (CFI), and Root Mean Square Error of Approximation (RMSEA). For the first three indices values of at least 0.90 are required to accept the model, for the latter a value smaller than 0.1 is indicating an acceptable fit [59].

In order to analyze the mode as a whole the structural equation modeling technique was applied. All external factors were correlated with each other in the model because literature did not explicitly rejected existence of these correlations, but they were omitted in the figures to make models readable. Different models were created for the 


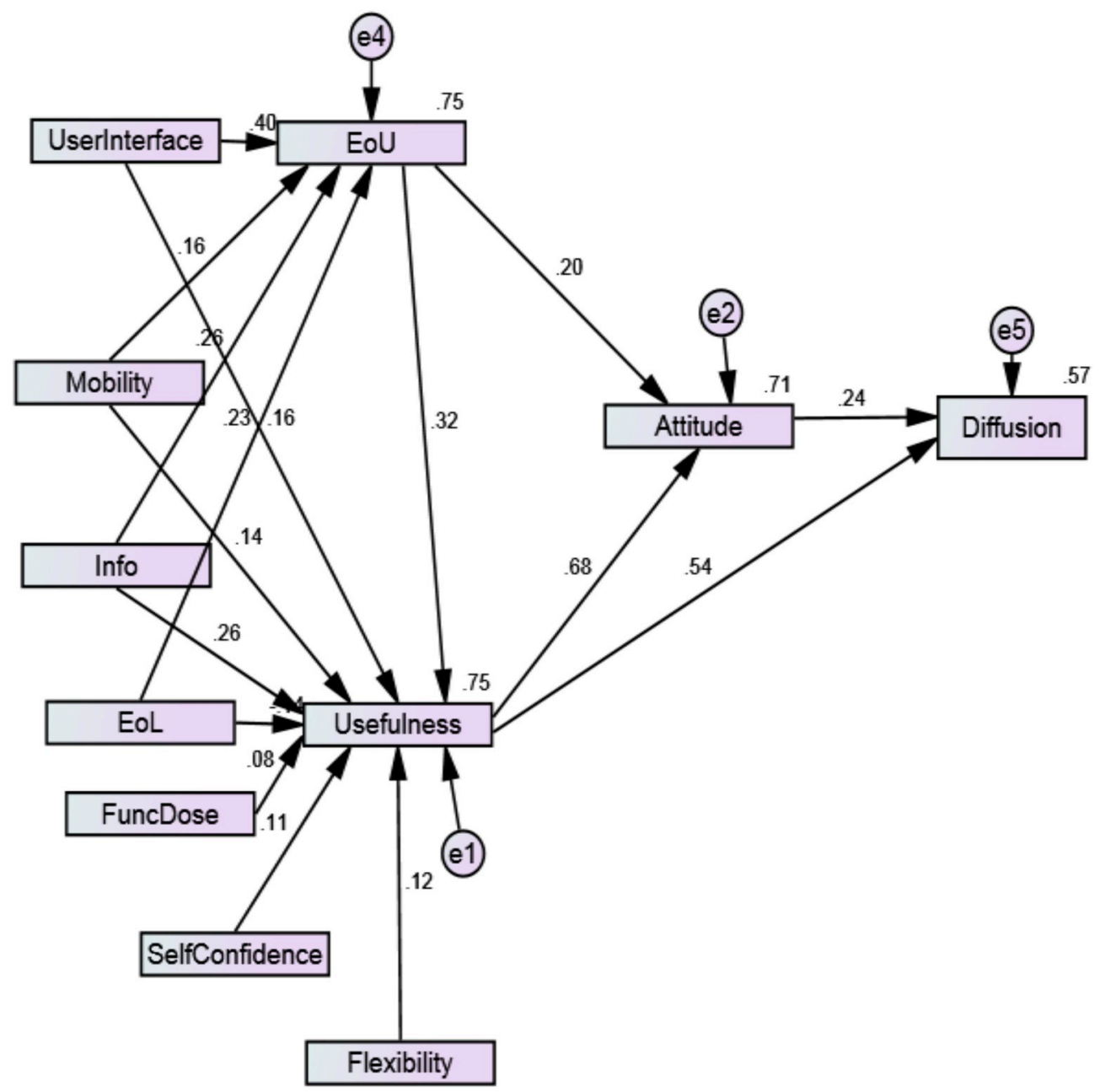

Fig. 1. EHR adoption model. Diffusion.

ultimate factors in order to get a more comprehensive view.

\subsection{Diffusion}

The p-value for chi-square test of 0.029 indicated that the hypothesis of the exact fit was not rejected. All fit indexes indicated a good fit of the model (Fig. 1) to the data (Table 1).

During the analysis of regression weights it was revealed that all the relationships among items are positive and significant. These findings supported the proposed hypothesis and the results of multiple regression analysis performed before.

Diffusion was found to be significantly and positively affected by the attitude toward the systems and its perceived usefulness, which corresponded with hypothesis three and four. The coefficient between perceived usefulness and EHR diffusion was calculated to be 0.54 $(\mathrm{p}<0.001)$, whereas between attitude and diffusion it was 0.24 ( $\mathrm{p}<0.001$ ), suggesting that greater diffusion rates could be reached

Table 1

Model fit.

\begin{tabular}{lll}
\hline $\begin{array}{l}\text { Model/Fit } \\
\text { estimate }\end{array}$ & Values & Recommendations \\
\hline$\chi^{2} / \mathrm{df}$ & 1.626 with $\mathrm{p}=0.029$ & $<3$ \\
TLI & 0.982 & $\geq 0.9$ \\
CFI & 0.994 & $\geq 0.97$ \\
RMSEA & 0.044 with $90 \%$ confidence interval from & $<0.1$ \\
& 0.014 to 0.069 and pclose value 0.610 &
\end{tabular}

when EHR system was able to carry out its assigned tasks and provided clear benefits to staff.

\subsection{Infusion}

The p-value for chi-square test of 0.000 indicated that the hypothesis of the exact fit was not rejected. The other fit indexes indicated an acceptable fit of the model to the data. The pclose value for RMSEA test of 0.142 showed that the hypothesis of the close fit was not rejected (Table 2).

The analyzed relationships (Fig. 2) were positive and significant ( $\mathrm{p}<0.05$ ). The hypotheses described above were all supported. The findings were consistent with the results of multiple regression analysis shown before.

The analysis revealed that perceived ease of use and usefulness positively and significantly affected EHR infusion. These findings supported the $\mathrm{H} 1$ and $\mathrm{H} 3$. The stronger association was found to be

Table 2

Model fit.

\begin{tabular}{lll}
\hline $\begin{array}{l}\text { Model/Fit } \\
\text { estimate }\end{array}$ & Values & Recommendations \\
\hline$\chi^{2} / \mathrm{df}$ & 2.299 with $\mathrm{p}=0.000$ & $<3$ \\
TLI & 0.961 & $\geq 0.9$ \\
CFI & 0.987 & $\geq 0.97$ \\
RMSEA & 0.064 with $90 \%$ confidence interval from & $<0.1$ \\
& 0.041 to 0.087 and pclose value 0.143 & \\
\hline
\end{tabular}




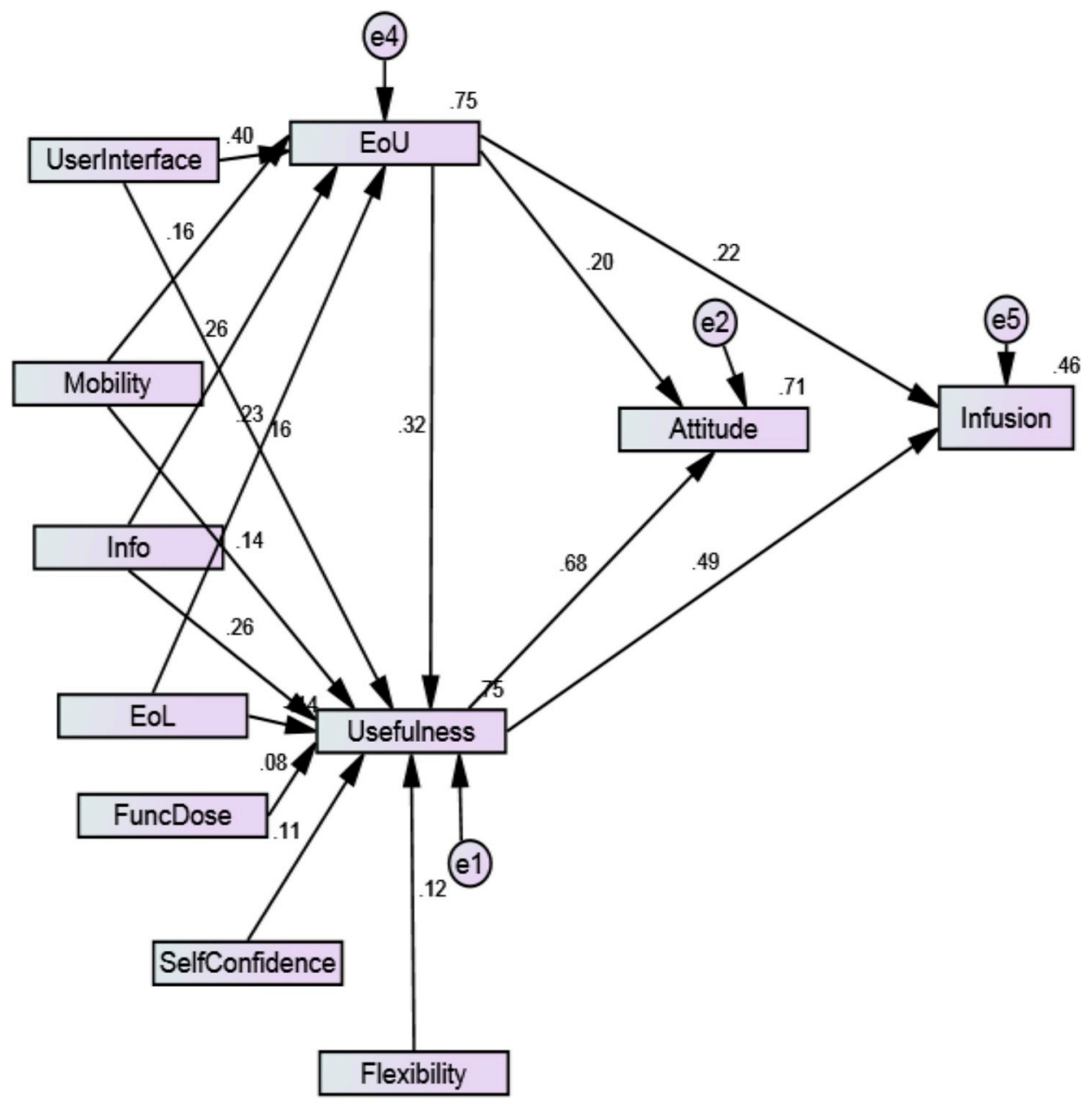

Fig. 2. EHR adoption model. Infusion.

between EHR infusion and perceived usefulness $(0.49, \mathrm{p}<0.001)$, whereas the perceived ease of use had an effect of 0.22 ( $\mathrm{p}<0.001$ ), which is consistent with the results from several other studies of TAM applications [34]. The findings suggest that the system that is compatible with users' work practices and is improving their performances will be better integrated in their everyday work processes and will lead to new work patterns.

\subsection{Satisfaction}

Though the p-value for chi-square test 0.000 indicated that the hypothesis of the exact fit was rejected, the other fit indexes indicated an acceptable fit of the model (Fig. 3) to the data. The pclose value for RMSEA test of 0.142 showed that the hypothesis of the close fit was not rejected (Table 3 ).

During the analysis of regression weights it was revealed that all the relationships between items were positive and significant. These findings supported the hypotheses $\mathrm{H} 1$ to $\mathrm{H} 17$ and the results of multiple regression analysis presented above.

According to the analysis satisfaction among physicians depended on perceived ease of use and perceived usefulness. The coefficients were $0.46(\mathrm{p}<0.001)$ and $0.44(\mathrm{p}<0.001)$ respectively. It indicated that both perceived ease of use and perceived usefulness had practically equal effect on the level of satisfaction. These findings were consistent with other studies in the field of healthcare IT adoption [28-30]. Users' satisfaction can only be reached when a system not only provides clear benefits and improves their performance but also delivers pleasant and unobstructed experience.

\subsection{Quality of Care}

Though the p-value for chi-square test 0.000 indicated that the hypothesis of the exact fit was rejected, the other fit indexes indicated an acceptable fit of the model (Fig. 4) to the data. The pclose value for RMSEA test of 0.142 showed that the hypothesis of the close fit was not rejected (Table 4).

During the analysis of regression weights it was revealed that all the relationships between items were positive and significant. These findings corresponded with the results obtained by Mustafa Kok and colleagues [60]. The hypotheses one and two were also supported. Perceived usefulness had a major effect on the quality of care with the coefficient 0.55 ( $p<0.001$ ), whereas attitude had a weight of 0.24 ( $\mathrm{p}<0.001$ ). These findings suggest that while it is important to ensure positive attitude toward EHRs among physicians, it is much more crucial to deliver a system that would meet users' requirement and efficiently perform tasks they need.

\section{Discussion}

The results obtained with SEM technique support the results from the multiple regression analysis. All the models fit acceptably indicating the adequate explanation of the data.

All the proposed hypothesizes were supported. Usefulness and Attitude were direct determinants of Quality of Care with coefficients $0.545(\mathrm{p}<0.001)$ and $0.242(\mathrm{p}<0.001)$ respectively. Ease of Use and Usefulness positively and significantly affected Satisfaction with coefficients $0.22(\mathrm{p}<0.001)$ and $0.49(\mathrm{p}<0.001)$ respectively. 


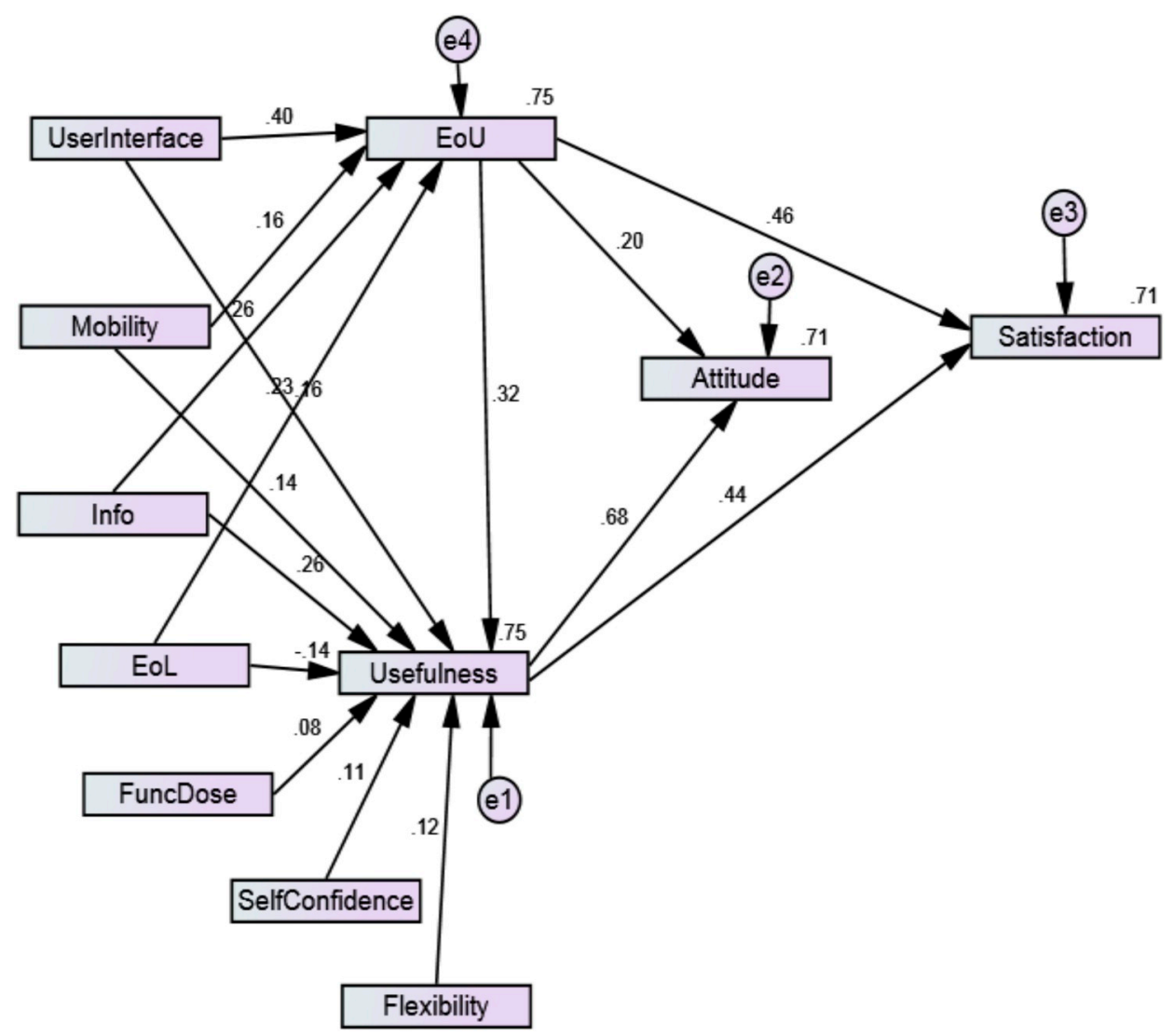

Fig. 3. EHR adoption model. Satisfaction.

Table 3

Model fit.

\begin{tabular}{lll}
\hline $\begin{array}{l}\text { Model/Fit } \\
\text { estimate }\end{array}$ & Values & Recommendations \\
\hline$\chi^{2} / \mathrm{df}$ & 3.008 with $\mathrm{p}=0.000$ & $<3$ \\
TLI & 0.945 & $\geq 0.9$ \\
CFI & 0.981 & $\geq 0.97$ \\
RMSEA & 0.08 with $90 \%$ confidence interval from & $<0.1$ \\
& 0.058 to 0.101 and pclose value 0.012 & \\
\hline
\end{tabular}

There were direct effects of Ease of Use and Usefulness on Infusion, with regression weights at $0.22(\mathrm{p}<0.001)$ and $0.49(\mathrm{p}<0.001)$. Diffusion was affected by Attitude and Usefulness with coefficients 0.24 ( $\mathrm{p}<0.001)$ and $0.54(\mathrm{p}<0.001)$ respectively. It could be concluded that Usefulness had a major effect on all four parameters that determined users' adoption.

Analysis of the relationships between intermediate constructs showed that Attitude was dependent on Usefulness with coefficient 0.681 ( $p<0.001$ ) and on Ease of Use with coefficient 0.197 ( $p<0.001)$. Ease of Use had a direct effect on Usefulness with weight 0.32 ( $\mathrm{p}<0.001)$ and an indirect effect on Attitude. The results were consistent with Davis' findings [6].

Information Quality, Software Flexibility, Software Mobility, Self Confidence of the user, User Interface, Dose Functionality of the software, and Ease of Learning significantly and positively affected Usefulness. Information Quality has the biggest weight among external factors (0.26, p < 0.001), Software Flexibility and Mobility, as well as User Interface and Users' confidence had weights from 0.105 to 0.156 , and the Dose Functionality had the smallest impact at 0.08 level ( $\mathrm{p}<0.05$ ). The importance of supporting an adequate level of data quality was underlined by many practitioners and researchers [50], as inaccurate and erroneous data entry would result in poor results ("garbage in - garbage out") and significantly decreased Usefulness of the system. Other factors, as flexibility and mobility of the system, user interface made working process easier, created more favorable environment, thus users saw benefits of a system and tried to make use of it.

Ease of use was significantly and positively affected by information quality, software mobility and accessibility, user interface, and ease of learning. The most influential factor was User Interface (0.40, $\mathrm{p}<0.001$ ), Information Quality and Software Flexibility had weights $0.23(\mathrm{p}<0.001)$ and $0.26(\mathrm{p}<0.001)$ respectively, and Ease of Learning had a coefficient of $0.16(\mathrm{p}<0.001)$.

During this study main adoption factors of EHR system usage have been analyzed. The results of the study present value for developer of EHR systems, as well as for policymakers and decision makers at hospitals who are responsible for choosing a particular system, and for those who are in charge of implementation and trainings.

Alignment with existing workflows and physicians' daily tasks was found to be a very important factor that had an effect on EHR adoption. Thus it can be suggested that developers should pay special attention to studying daily routines at clinics environment as well as emergency situations that can occur. EHR systems should be adapted to fit into clinic's settings, which would make physicians to use it more efficiently. It's also important for managers at clinics who are responsible for EHR system acquisition to make sure that they have chosen a product that does not require changing existing processes.

Usefulness the system was found to be highly dependent on the functionalities of the system and its integration with other software products. Such functionalities as keeping the correct information about medicine dosages, hints and tutorials are of great demand. Adding a "complaint" button to a system, so that users can report bugs and problems, would make people feel that their opinions are valuable. Developers should consider adding these features to their system.

Other factors that developers and software architects should take 


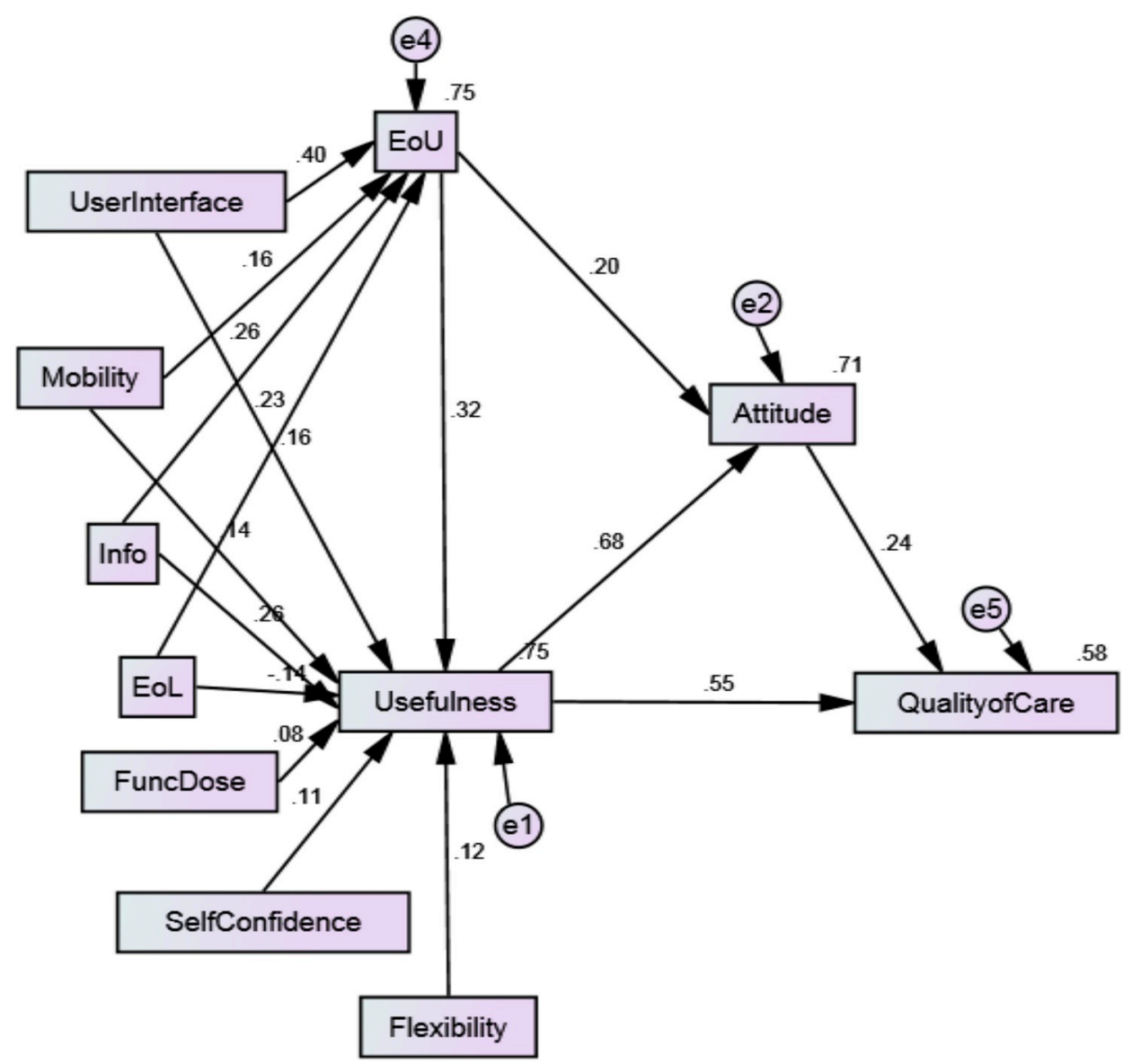

Fig. 4. EHR adoption model. Quality of care.

Table 4

Model fit.

\begin{tabular}{lll}
\hline $\begin{array}{l}\text { Model/Fit } \\
\text { estimate }\end{array}$ & Values & Recommendations \\
\hline$\chi 2 / \mathrm{df}$ & 3.037 with $\mathrm{p}=0.000$ & $<3$ \\
TLI & 0.942 & $\geq 0.9$ \\
CFI & 0.980 & $\geq 0.97$ \\
RMSEA & 0.08 with $90 \%$ confidence interval from & $<0.1$ \\
& 0.059 to 0.102 and pclose value 0.011 & \\
\hline
\end{tabular}

into account are information quality, user interface, accessibility and mobility. Information quality is a complex factor that it defined by completeness of information, its accuracy, reliability, dateness. User interface that is not convenient may result in less efficient use, frustration and decreased satisfaction. Thus developers should design a system that is convenient to use, where all graphs, bottoms, input fields are appropriate, and the overall feel is satisfactory. User testing and demonstrations could help to better understand needs and requirements. Such research methods, such ethnographic observations and focus groups, can be helpful in identifying and prioritizing users' tasks in clinical environment and improving interface design and usability of EHRs [46]. Quick access to clinical information, especially in emergency cases and from outside of the hospital, needs to be implemented as well.

Ease of learning is another important factor that affects both perceived usefulness and perceived ease of use of the system. EHR system should be designed the way that a user does not have to put much effort while starting to use it. The first negative impression can outweigh all the potential benefits of the system.

The study revealed that individual's self-confidence was an important factor that had a positive effect in perceived usefulness. Physicians who had more computer experience would find the system more useful. This suggests that before purchasing an EHR system hospitals policymakers and managers should evaluate what the average level of computer literacy among clinicians is, identify areas that can be improved and provide additional trainings to those who are lagging behind.

The outputs of this study and the developed models are also useful for further researches. The proposed models can be expanded and generalized for different settings and countries.

Recent research [61-64] have advanced our knowledge in technology adoption in areas including wearables, smartphones and other geographic areas.

\section{Conclusions and further research}

Ben-Tzion Karsh and colleagues in the paper "Health information technology: fallacies and sober realities" [50] among different issues associated with HIT adoption mention that often the decision about purchasing and implementing an EHR system is made by administration rather than future users of the system. Thus, the authors argue that many EHR systems are designed to meet the requirements of people who do not have to use the system. This mismatch can lead to inefficiency, workarounds, and poor adoption. Another benefit of such studies is that developers, systems architects, project managers would have better understanding of users' needs and will be able to create solutions to meet the requirements. According to the study efficient use of EHR systems is mainly affected by the functionalities of the systems, user interface, integration, task-technology fit, information quality and accessibility. Successful implementations may only be reached when users are satisfied. This work helps to better understanding what factors 
affect satisfaction and what actions need to be done to improve chances of a system's success.

\section{References}

[1] B. Hamilton, An introduction to electronic health records, In Electronic Health Records, Career Education, 2010, pp. 1-15.

[2] K.A. Wager, F.W. Lee, J.P. Glaser, History and Evolution of Health Care Information Systems, In Health Care Information Systems, 2009, pp. 87-109.

[3] EHR Adoption \& Meaningful Use Progress Is Assessed in New Data Briefs | Health IT Buzz. (2013) [Online] http://www.healthit.gov/buzz-blog/meaningful-use/ehradoption-meaningful-use-progress-assessed-data-briefs/ 05-Mar.

[4] D.A. Ludwick, J. Doucette, Adopting electronic medical records in primary care: lessons learned from health information systems implementation experience in seven countries, Int. J. Med. Inform. 78 (1) (Jan. 2009) 22-31.

[5] A.H. Hennington, B.D. Janz, Information systems and healthcare XVI: physician adoption of electronic medical records: applying the UTAUT model in a healthcare context, Commun. Assoc. Inf. Syst. 19 (2007) 60-80.

[6] F.D. Davis, Computer and Information Systems Graduate Schooi of Business Administration Univeirsity of Michigan, (1989) no. September.

[7] N. Basoglu, T. Daim, O. Kerimoglu, Organizational adoption of enterprise resource planning systems: a conceptual framework, J. High Technol. Manag. Res. 18 (1) (Jan. 2007) 73-97.

[8] B. Kargin, N. Basoglu, Adoption factors of mobile services, International Conference on Mobile Business, 2006, pp. 15-34.

[9] E. Polat, N. Basoglu, Effects of adaptivity and other external variables on mobile service adoption, Hawaii International Conference on System Sciences, 2009, pp. 3364-3381.

[10] N. Basoglu, T. Daim, İ. Ișkın, B. Aydınoglu, M. Öztürk, New product development for the healthcare industry: a case study of diet software, Health Policy Technol. 1 (2) (Jun. 2012) 93-104.

[11] C.O. Seneler, N. Basoglu, T. Daim, Exploring user adoption of online services: a prototype driven framework for service design and development, J. Entreprise Info. Manag. 23 (4) (2010) 417-438.

[12] N. Basoglu, T.U. Daim, U. Topacan, Determining patient preferences for remote monitoring, J. Med. Syst. 36 (3) (Jun. 2012) 1389-1401.

[13] U. Topacan, N. Basoglu, T.U. Daim, Exploring the success factors of health information service adoption, Portland International Conference on Management of Engineering \& Technology, 2008, pp. 2453-2461.

[14] O. Kok, D. Basoglu, T. Daim, Exploring the Success Factors of Electronic Health Record Systems Adoption, Technology Management in the Energy Smart World, Proceedings of PICMET 2011 Conference, 2011, pp. 2943-2950.

[15] O. Kok, D. Basoglu, T. Daim, Exploring the Success Factors of Electronic Health Record Systems Adoption, Technology Management for Emerging Technologies, Proceedings of PICMET 2012 Conference, 2012, pp. 1471-1477.

[16] T. Daim, N. Behkami, N. Basoglu, O. Kok, L. Hogaboam, Health Care Technology Innovation Adoption, Springer, (2016).

[17] D. Spatar, T. Daim, N. Basoglu, Adoption of Electronic Health Records, The 23rd International Conference for Management of Technology, IAMOT, 2014.

[18] R.J. Holden, B.-T. Karsh, The Technology Acceptance Model: its past and its future in health care, J. Biomed. Inform. 43 (2010) 159-172.

[19] M.E. Morton, S. Wiedenbeck, A Framework for Predicting EHR Adoption Attitudes: a Physician Survey, Perspectives in health information management/AHIMA, American Health Information Management Association vol. 6, (Jan. 2009) 1a.

[20] C.S. Gadd, L.E. Penrod, "Assessing physician attitudes regarding use of an out patient EMR: a longitudinal, multi-practice study.," Proceedings/AMIA . Annual Symposium. AMIA Symposium, Jan. 2001, pp. 194-198.

[21] J. Handy, R. Whiddett, I. Hunter, User acceptance of inter-organizational electronic medical records, Health Inf. J. 7 (2) (Jun. 2001) 103-107.

[22] D.A. Adams, R.R. Nelson, P.A. Todd, B.D.A. Adams, "Perceived usefulness, ease of use, and usage of information Technology : a replication, MIS Quaterly 16 (2) (1992) 227-247.

[23] A.H. Segars, V. Grover, "Re-Examining perceived ease of use and Usefulness : a confirmatory factor Analysis, MIS Quaterly 17 (4) (1993) 517-525.

[24] R.J. Holden, B.-T. Karsh, The technology acceptance model: its past and its future in health care, J. Biomed. Inform. 43 (1) (Feb. 2010) 159-172.

[25] M.A. Wilkins, Factors Influencing Acceptance of Electronic Health Records in Hospitals vol. 6, Perspectives in health information management/AHIMA, American Health Information Management Association, Jan. 2009, pp. 1-20.

[26] W.H. DeLone, E.R. McLean, Information systems success: the quest for the dependent variable, Inf. Syst. Res. 3 (1) (1992) 60-95 Mar.

[27] J.L. Sánchez, S. Savin, V. Vasileva, Key Success Factors in Implementing Electronic Medical Records in, University Hospital of Rennes, 2005.

[28] F. Lee, J.M. Teich, C.D. Spurr, D.W. Bates, Implementation of physician order entry: user satisfaction and self-reported usage patterns, J. Am. Med. Inform. Assoc.: JAMIA 3 (1) (1996) 42-55.

[29] R.T. O'Connell, C. Cho, N. Shah, E. Al, Take note(s): differential EHR satisfaction with two implementations under one roof, J. Am. Med. Inform. Assoc. 11 (1) (2004) $43-50$.

[30] L.S. Liu, P.C. Shih, G.R. Hayes, Barriers to the adoption and use of personal health record systems, Proceedings of the 2011 iConference on - iConference, vol. 11, 2011, pp. 363-370.

[31] R.W. Zmud, L.E. Apple, Measuring technology incorporation/infusion, J. Prod. Innov. Manag. 9 (2) (Jun. 1992) 148-155.

[32] D.B. Meister, D.R. Compeau, Infusion of Innovative Adoption: an Individual Perspective, (1992), pp. 23-33 2002.
[33] Ben-Tzion Karsh, et al., Health Information Technology: Fallacies and Sober Realities vol. 6, (2010), p. 30007606.

[34] P.Y.K. Chau, P.J.-H. Hu, Information technology acceptance by individual professionals: a model comparison approach, Decis. Sci. J. 32 (4) (Dec. 2001) 699-719.

[35] S.E. Ross, L.M. Schilling, D.H. Fernald, A.J. Davidson, D.R. West, Health information exchange in small-to-medium sized family medicine practices: motivators, barriers, and potential facilitators of adoption, Int. J. Med. Inform. 79 (2) (Feb. 2010) 123-129.

[36] H. Greenspun, Issue Brief: Physician Perspectives about Health Information Technology, (2012).

[37] B. Collins, M. Wagner, Early experiences in using computerized patient record data for monitoring charting compliance, supporting quality initiatives and assisting with accurate charging at Allina Hospitals \& Clinics, Int. J. Med. Inform. 74 (11-12) (Dec. 2005) 917-925.

[38] P.J.B. Brown, V. Warmington, Data quality probes-exploiting and improving the quality of electronic patient record data and patient care, Int. J. Med. Inform. 68 (1-3) (Dec. 2002) 91-98.

[39] I. Cho, J. Kim, J.H. Kim, H.Y. Kim, Y. Kim, Design and implementation of a standards-based interoperable clinical decision support architecture in the context of the Korean EHR, Int. J. Med. Inform. 79 (9) (Sep. 2010) 611-622.

[40] A. Likourezos, D.B. Chalfin, D.G. Murphy, B. Sommer, K. Darcy, S.J. Davidson, Physician and nurse satisfaction with an electronic medical record system, J. Emerg. Med. 27 (4) (Nov. 2004) 419-424.

[41] E.W. Ford, N. Menachemi, L.T. Peterson, T.R. Huerta, Resistance is futile: but it is slowing the pace of EHR adoption nonetheless, J. Am. Med. Inform. Assoc.: JAMIA 16 (3) (2014) 274-281.

[42] R.G. Fichman, The diffusion and assimilation of information technology innovations to appear in, In Framing the Domains of IT Management: Projecting the Future through the Past, 2000, pp. 105-128.

[43] S. Hyun, S.B. Johnson, P.D. Stetson, S. Bakken, Development and evaluation of nursing user interface screens using multiple methods, J. Biomed. Inform. 42 (6) (Dec. 2009) 1004-1012.

[44] D. Yoon, B.-C. Chang, S.W. Kang, H. Bae, R.W. Park, Adoption of electronic health records in Korean tertiary teaching and general hospitals, Int. J. Med. Inform. 81 (3) (2012) 196-203 Mar.

[45] P.J. Toussaint, H. Lodder, Component-based development for supporting workflows in hospitals, Int. J. Med. Inform. 52 (1-3) (1998) 53-60.

[46] A.F. Rose, J.L. Schnipper, E.R. Park, E.G. Poon, Q. Li, B. Middleton, Using qualitative studies to improve the usability of an EMR, J. Biomed. Inform. 38 (1) (Feb. 2005) 51-60.

[47] P.J. Edwards, K.P. Moloney, J. a. Jacko, F. Sainfort, Evaluating usability of a commercial electronic health record: a case study, Int. J. Hum. Comput. Stud. 66 (10) (Oct. 2008) 718-728.

[48] R. Patterson, Physician satisfaction with order entry systems, J. Am. Med. Inform. Assoc.: JAMIA 9 (3) (2001) 308-309 author reply 309.

[49] K. Häyrinen, K. Saranto, P. Nykänen, Definition, structure, content, use and impacts of electronic health records: a review of the research literature, Int. J. Med. Inform. 77 (5) (May 2008) 291-304.

[50] B.-T. Karsh, M.B. Weinger, P. a Abbott, R.L. Wears, Health information technology: fallacies and sober realities, J. Am. Med. Inform. Assoc.: JAMIA 17 (6) (2010) 617-623.

[51] L.C. Burton, G.F. Anderson, I.W. Kues, Using electronic health records to help coordinate care, Milbank Q. 82 (3) (2004) 457-481 table of contents, Jan.

[52] M. Staroselsky, L. a Volk, R. Tsurikova, L.P. Newmark, M. Lippincott, I. Litvak, A. Kittler, T. Wang, J. Wald, D.W. Bates, "An effort to improve electronic health record medication list accuracy between visits: patients' and physicians' response, Int. J. Med. Inform. 77 (3) (2008) 153-160 Mar.

[53] X. Wang, H. Chase, M. Markatou, G. Hripcsak, C. Friedman, Selecting information in electronic health records for knowledge acquisition, J. Biomed. Inform. 43 (4) (Aug. 2010) 595-601.

[54] V. Ilie, C. Van Slyke, M. a. Parikh, J.F. Courtney, "Paper versus electronic medical records: the effects of access on physicians' decisions to use complex information technologies, Decis. Sci. J. 40 (2) (May 2009) 213-241.

[55] J. Zhang, M.F. Walji, TURF: toward a unified framework of EHR usability, J. Biomed. Inform. 44 (6) (Dec. 2011) 1056-1067.

[56] O. Kerimoglu, N. Basoglu, T. Daim, Organizational adoption of information tech nologies: case of enterprise resource planning systems, J. High Technol. Manag. Res. 19 (1) (Jan. 2008) 21-35.

[57] D. Pongpattrachai, P. Cragg, R. Fisher, IT infusion within the audit process: spreadsheet use in small audit firms, Int. J. Account. Inf. Syst. 15 (1) (March 2014) $26-46$.

[58] Eda Corbacioglu, Utilization of icons and symbols in advertisement posters (in French), J. Int. Soc. Res. 7 (34) (Nov 2014).

[59] J. J. Hox, "An Introduction to Structural Equation Modeling vol. 1," pp. 1-17.

[60] O.M. Kök, Adoption Factors of Electronic Health Record Systems, unpublished thesis (2012).

[61] A.E. Ok, N. Basoglu, T. Daim, What will it take to adopt smart glasses: a consumer choice based review? Technol. Soc. 50 (August 2017) 50-56.

[62] N. Behkami, Daim T "health information technology adoption", Health Policy and Technology 5 (No 2) (2016) 166-188.

[63] S. Cayir, N. Basoglu, T. Daim, A study on the relationship between task, information, and individual performance, Technol. Soc. 46 (2016) 1-9.

[64] F. Aldahaban, T. Daim, R. Harmon, Exploring the adoption and use of the smartphone technology in emerging regions: case of Saudi arabia, Portland International Conference on Management of Engineering and Technology Proceedings, 2016 Technology Management for Social Innovation. 